Applied Surface Science 492 (2019) 1-7

Full length article

\title{
Obtaining tailored surface characteristics by combining shot peening and electropolishing on 316L stainless steel
}

\author{
P. Lopez-Ruiz"a, , M.B. Garcia-Blanco ${ }^{a}$, G. Varaa , I. Fernández-Pariente ${ }^{b}$, M. Guaglianoc, \\ S. Bagherifard \\ a CIDETEC, P० MIRAMÓN 196, 20014 DONOSTIA, SAN SEBASTIÁN, SPAIN \\ ${ }^{\mathrm{b}}$ University of Oviedo, DEPARTMENT of MATERIAL AND METALLURGY Engineering, CAMPUS de Viesques, 33203 Gijón, SPAIN \\ ${ }^{c}$ Politecnico di MILANO, DEPARTMENT of MECHANICAL Engineering, VIA LA MASA 1, 20156 MiLAN, ItALY
}

\section{A R T I C LEIN F O}

\section{Keywords:}

Severe shot peening

Electropolishing

$316 \mathrm{~L}$

Surface roughness

Surface morphology

\begin{abstract}
A B T R A C T
Shot peening is a well-established surface treatment commonly used to improve mechanical properties of ma-terial's surfaces. Studies have shown notable enhancement of fatigue strength, wear, scratch and corrosion re- sistance and fretting properties as a result of an intensive shot peening treatment, the so-called severe shot peening. Nevertheless, this process has some drawbacks including quite high surface roughness and possible embedment of shot residuals at the treated surface, which can have adverse effects depending on the final application. In this paper, electropolishing has been evaluated as a cleaning post-treatment for shot peened surfaces of 316L stainless steel. For this purpose, electropolishing voltage has been varied with the aim of obtaining clean and smoother surfaces without sacrificing the mechanical improvements produced by shot pe- ening. The treated surfaces have been characterized considering surface roughness, morphology, wettability, residual stresses and microhardness evolution after various shot peening treatments combined with electro- polishing using different parameter setups to identify the most promising combinations.
\end{abstract}

\section{Introduction}

Shot peening is an impact-based surface treatment usually applied for fatigue strength improvement of structural components. During the process, small spherical peening media impact a surface with enough energy to provide surface plastic deformation. The reiterated impacts produce compressive residual stresses and harden the near surface layer of materials, while increasing the surface roughness [1].

Severe shot peening (SSP) is a particular peening process carried out by modifying the main parameters that control the peening process, namely surface coverage and Almen intensity, in order to obtain higher energy impacts. Almen intensity is defined as the arc height of an standard Almen test strip measured at a coverage of 98\% (corresponding to full coverage) by using an Almen gauge, while surface coverage is the ratio of the area covered by plastic indentation to the whole treated surface area [2]. The emerging SSP method has been recently applied to different materials such as AISI 316L [3], steel [4], aluminium [5], cast iron [6] and AZ31 magnesium alloy [7]. The results of these investigations indicated that SSP is highly efficient in enhancing mechanical properties, inducing notable grain refinement and compressive residual stresses on the surface layer of the treated material [8-10]. Moreover, enhanced mechanical properties in terms of fatigue strength, wear, scratch and corrosion resistance were achieved after SSP process, without compromising the chemical composition or biocompatibility of the as received materials [7]. Through SSP, the thickness of the small initial refined zone, caused by the cutting method, was increased intensively and modified into a distinct refined structure. Additionally, surface roughness and surface wettability in- crease after SSP. The obtained surface properties are desirable for biomedical applications as besides enhancing mechanical performance, they can reduce bacterial infection risk, promote interaction with the surrounding tissue and potentially reduce the rate of loosening and migration of the biomedical device [11].

On a more general note, although surface roughness induced by SSP was found to be significantly important to inhibit bacterial adhesion [3], this particularly disordered surface topography could cause pos- sible limitations for specific applications [12]; for example vascular implants or stents can notably benefit from shot peening based treat- ments, however they usually need a smooth polished surface. Other fields of applications that also require polished surfaces but could take benefit from the other properties provided by shot peening process are, among others, components subjected to dynamic loads in applications

\footnotetext{
* Corresponding author.

E-MAIL ADDRESS: plopez@cidetec.es (P. Lopez-Ruiz).
} 
such as machinery, aeronautics or automotive. For instance, a recent investigation has revealed that the contact fatigue resistance of shot peened austempered ductile iron gears has poor performance due to the negative impact resulting from the roughened surface [13]; this adverse effect of surface roughness could overshadow the benefits prompted by the shot peening process, namely the induced compressive residual stresses, higher surface hardness as well as the grain refinement induced by SSP [13]. In these applications, the surface roughness reduction of the shot peened surfaces maintaining the properties provided by the process, could significantly improve the performance and service lifetime of components submitted to cyclic loads. An additional benefit of polishing shot peened surfaces was observed on Alloy 690 steam generator tubes of pressurized water reactors. A study has demonstrated that after the application of electropolishing (EP) on a shot peened surface, the corrosion rate of the component was reduced to almost a quarter of that obtained by shot peening only [14].

Another challenging issue that could impede successful application of shot peening is some fields for example in biomedical implants isthe potential presence of embedded shot fragments on the treated surfaces that makes the treated material prone to aseptic complications, besides introducing potential crack nucleation sites. Some studies have demonstrated that these particles could also be responsible for third-body wear and early implant failure [15]. Sand blasting, which has a similar concept to shot peening but uses less controlled media size and geometry, is commonly used in biomedical applications with the purpose of modifying the surface finish to make it more suitable for tissue integration [16]. However, there are reports revealing that residuals of pure corundum used as media for sand blasting left on the surface of the implant could generate later stage complications in maxillo-facial and orthopaedic surgeries $[17,18]$.

In this context, a strict post-treatment control after peening processes is necessary to decontaminate the surface and remove the remaining shot particles and provide a polished surface required in the target applications or to further improve other properties such as wear and corrosion resistance. Thus, suggesting a method that can provide more flexibility to control the surface characteristics induced by shot peening seems quite interesting.

Herein we aimed at evaluating the application of the EP process as a post-treatment to shot peened surfaces. Specifically, we studied the effect of EP on 316L stainless steel surfaces, treated by conventional shot peening (CSP) and severe shot peening (SSP).

$\mathrm{EP}$ is a surface finishing process in which the surface roughness is reduced through a selective electrochemical dissolution. The metal to be treated is immersed in an electrolyte, which must be carefully chosen for each system, anodically polarized and dissolved by applying a specific amount of current for a fixed period of time. The process is traditionally used in diverse applications to provide a clean, smooth and bright appearance. Moreover, EP surfaces could offer additional advantages including easier cleaning and maintenance, increasing corrosion resistance and reducing friction and wear for contact surfaces [19].

EP has been widely applied for different applications such as optical devices, high vacuum and nuclear applications and automotive or food industry among others [20,21]. In the field of biomedical implants, vascular implants such as cardiovascular devices, vascular stents are commonly electropolished to adjust their surface state for improved biocompatibility [22]. EP is required also for treating certain NiTi braided stents to achieve a medical-grade surface finish. In this latter, the thermally-grown oxide resulting from the shape-setting heat treatment, following the braiding must be removed by EP, which is also required to achieve optimum corrosion resistance [23].

The combination of shot peening and EP has been previously reported in the literature. As previously mentioned, recent studies demonstrated that the application of EP after shot peening has enhanced the corrosion behaviour of nickel-based alloys [13]. In other studies, suspension spring steels [24] or in carburized gears [25]. In the present paper, however, EP has been evaluated as a post-process after SSP treatment, which is more prone to shot fragmentation and embedment of shot residuals in the surface of the treated material due to the much higher kinetic energy of the process compared to shot peening and sand blasting.

Here we used EP to decontaminate the surface and to remove the residuals peening particles embedded in SSP treated 316L stainless steel, besides improving surface quality. CSP and not peened materials have been also considered as control series. Likewise, the effect of the electrochemical process on the surface roughness, wettability and mechanical properties of the peened surfaces have been evaluated in order to assess if a tailored surface roughness could be obtained without changing the mechanical benefits produced by the peening processes.

\section{Experimental procedure}

\subsection{MATERIAL}

Rectangular samples of $30 \times 25 \times 2 \mathrm{~mm}^{3}$ AISI 316L stainless steel (Acerinox) were employed in this work. The nominal chemical composition is provided in Table 1 .

\subsection{Shot peening TREATMENT (CSP AND SSP)}

Before EP, samples were subjected to CSP and SSP treatments using air blast shot peening machine. 'A' type Almen test strips were used to obtain Almen intensity. Table 2 presents the parameters used for each treatment.

\subsection{Electropolishing process}

EP experiments were performed on all series of samples applying constant voltage from $2 \mathrm{~V}$ to $7 \mathrm{~V}$ with an EA-PS 5040-40A power supply, using a two electrode system in a $1500 \mathrm{~mL}$ acid electrolyte bath $\left(\mathrm{H}_{3} \mathrm{PO}_{4} / \mathrm{H}_{2} \mathrm{SO}_{4} 3: 2\right)$ at $75{ }^{\circ} \mathrm{C}$. The anode of AISI 316L piece and the cathode of AISI 304 stainless steel foil were positioned at a distance of 3 $\mathrm{cm}$. The duration of the EP was set to $10 \mathrm{~min}$. Magnetic stirring was employed at the bottom of the electrolytic cell in order to maintain a controlled hydrodynamic. Subsequent to EP, substrates were rinsed with distilled water and dried in air.

\subsection{RoughnesS MEASUREMENTS AND SURFACE morphology}

Before characterization, the samples were cleaned using acetone and distilled water in an ultrasound bath for $15 \mathrm{~min}$ per each step. Then they were dried with warm air. The cleaning procedure is important especially for evaluating brightness and water contact angle, since the surface cleanness can significantly affect the output of these tests.

Surface roughness characterization was carried out using a Leica DCM 3D confocal microscope. The average value of standard surface roughness $S_{a}$ (arithmetical mean) is reported according to the ISO 25178 standard [26]. Two samples with same conditions were con- sidered and the measurements were performed on three random areas per sample.

The surface morphology of the treated samples was observed using a ZEISS Ultra Plus field emission scanning electron microscope (FE-SEM). In addition, surface contamination was analysed using energy dispersive X-ray spectrometer (EDS-EDAX).

Table 1

Nominal chemical composition of 316L stainless steel (\% mass).

\begin{tabular}{lllllllll}
\hline Element & $\mathrm{C}$ & $\mathrm{Cr}$ & $\mathrm{Mn}$ & $\mathrm{Mo}$ & $\mathrm{Ni}$ & $\mathrm{P}$ & $\mathrm{S}$ & $\mathrm{Si}$ \\
\hline \% Mass & 0.028 & 17.085 & 1.337 & 2.025 & 10.035 & 0.028 & 0.0010 .432
\end{tabular}


Table 2

Shot peening parameters.

\begin{tabular}{|c|c|c|c|}
\hline Type of treatment & Shot material and diameter & Almen intensity (0.0001 in.) & Surface coverage \\
\hline Not peened (NP) & - & - & - \\
\hline Conventional shot peening (CSP) & Zirconia & $8 \mathrm{~A}$ & $100 \%$ \\
\hline Severe shot peening (SSP) & $300 \mu \mathrm{m}$ & $10 \mathrm{~A}$ & $3000 \%$ \\
\hline
\end{tabular}

Table 3

Shot peening and electropolishing conditions.

\begin{tabular}{rllllll}
\hline \multicolumn{7}{c}{ EP parameters } \\
\cline { 2 - 6 } & No EP & $2 \mathrm{~V}$ & $3 \mathrm{~V}$ & $5 \mathrm{~V}$ & $7 \mathrm{~V}$ \\
\hline Shot peening treatment NP & NP & - & - & - & - \\
CSP & CSP & CSP-2 V & CSP-3 V & CSP-5 V & CSP-7 V \\
SSP & SSP & SSP-2 V & SSP-3 V & SSP-5 V & SSP-7 V
\end{tabular}

\subsection{SURFACE WETTABILITY MEASUREMENTS}

The wetting properties for different shot peened and electropolished surfaces were characterized by water contact angle measurements, using a CAM 200 goniometer system (KSV Instruments), at room temperature and ambient humidity. Two samples per each condition were used and three different locations of the surface were selected to obtain an average value and determine heterogeneity of the surfaces. Sessile drop method was employed using a droplet size of $15 \mu \mathrm{L}$.

\subsection{BrightnesS MEASUREMENTS}

Surface brightness was evaluated by a glossmetter, using a MicroTri-Gloss (BYK-Gardner GmbH). Two samples per each condition were evaluated and three random areas were measured on each sample with the incidence angle of $60^{\circ}$. The reported results correspond to the average of the measurements.

\subsection{RESIDUAL streSS MEASUREMENTS}

The distribution of the residual stresses was assessed by X-ray diffraction (XRD) analysis, using AST X-Stress 3000 portable X-ray diffractometer $\left(\mathrm{CrK} \alpha\right.$ radiation $(\lambda K \alpha 1=2.2898 \AA), \sin ^{2}(\phi)$ method, diffraction angle $(2 \theta)$ of $128.8^{\circ}$ corresponding to $\{220\}$-reflex scanned with a total of 7 Chi tilts in the range of $-45^{\circ}$ to $45^{\circ}$ along three rotation of $0^{\circ}$ and $90^{\circ}$. The profiles of the residual stresses induced by CSP and SSP treatments were characterized on one sample per treatment.

Measurements were carried out in depth by removing a very thin layer of material $(0.02 \mathrm{~mm}$ close to the surface and $0.06 \mathrm{~mm}$ at higher depths), measured with a Mitutoyo micrometer precision IDCH0530/ 0560 after each EP step, where a solution of acetic acid (94\%) and perchloric acid $(6 \%)$ was used.

\subsection{MICROHARDNESS MEASUREMENTS}

Vickers microhardness measurements were performed on samples for each condition that were cut in cross-section and embedded in a phenollic hot mounting resin. Metallographic preparation was performed using SiC papers up to FEPA 4000 followed by polishing with polycrystalline diamond water based suspension up to $1 \mu \mathrm{m}$. The tests were performed using a Fischer HM2000 microhardness tester, equipped with a diamond Vickers indenter and load of $200 \mathrm{gf}$ (HV0.2) during 10s. The measurements were performed along three parallel paths, starting from shot peened surface down to the core material (with a step size of $0.1 \mathrm{~mm}$ ).

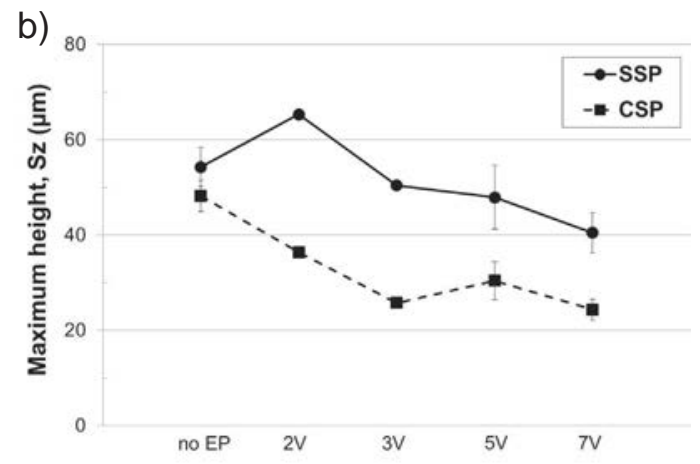

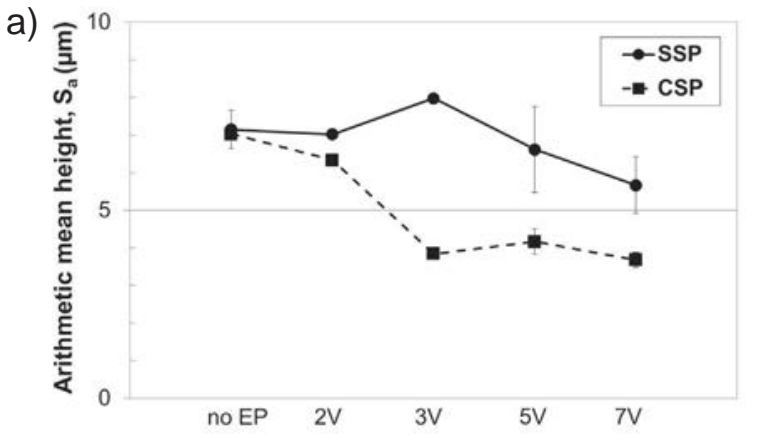

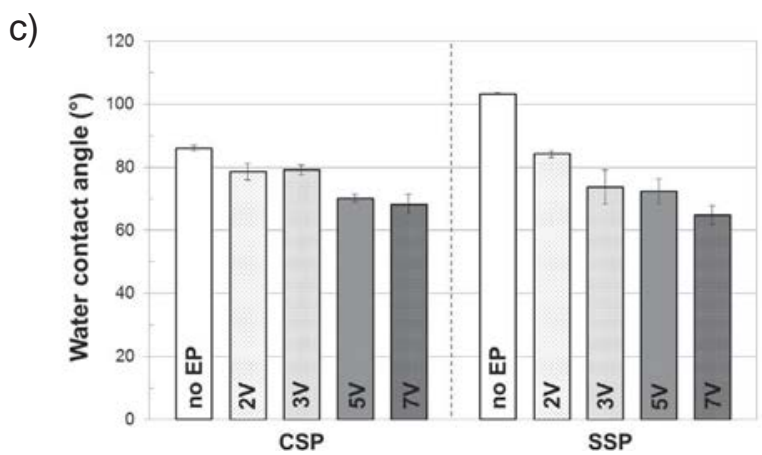

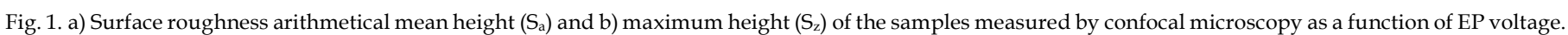
c) Water contact angle results for the shot peened samples as a function of EP voltage. 


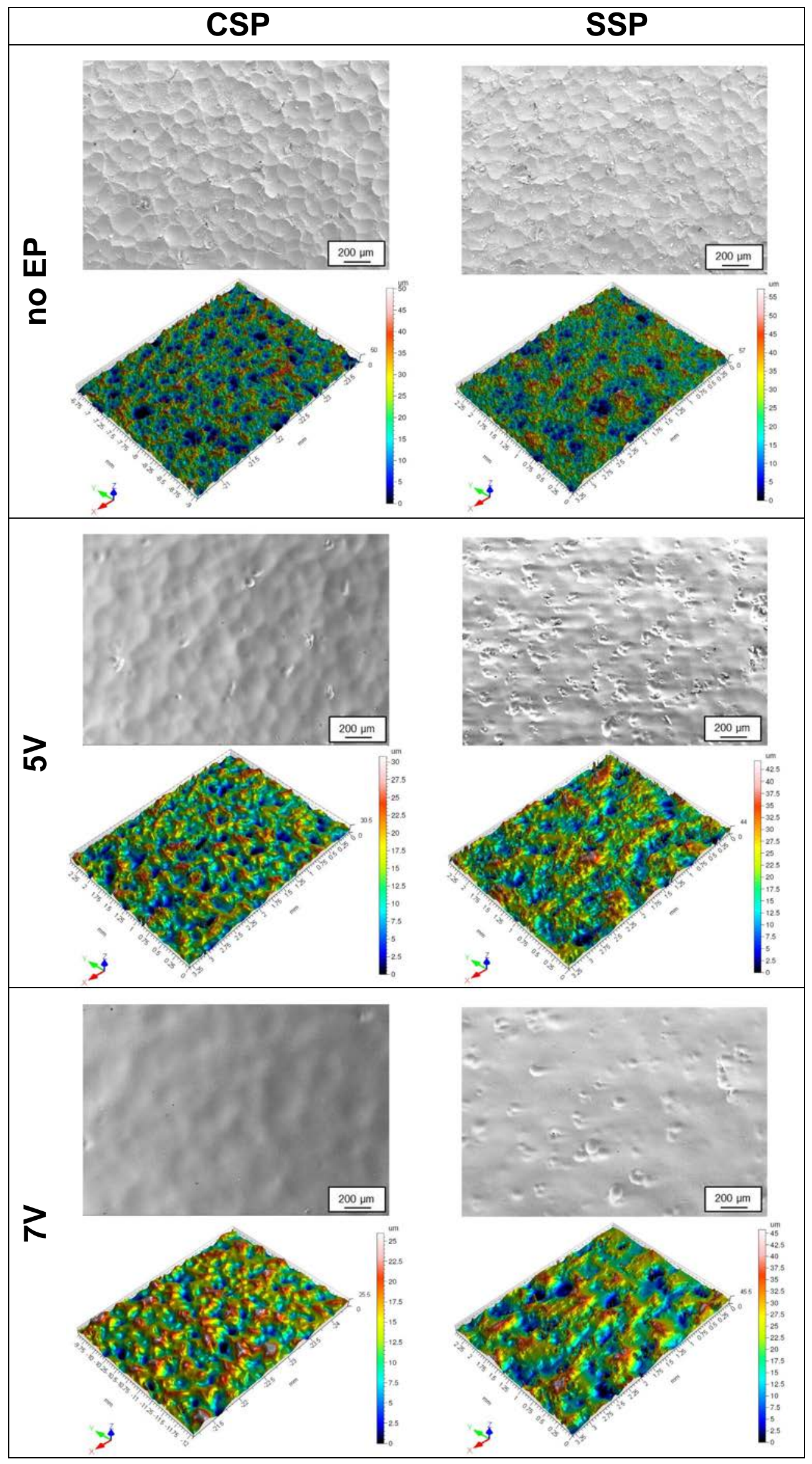

Fig. 2. FE-SEM micrographs and confocal microscope 3D representation of shot peened samples' surface morphology before and after EP. 


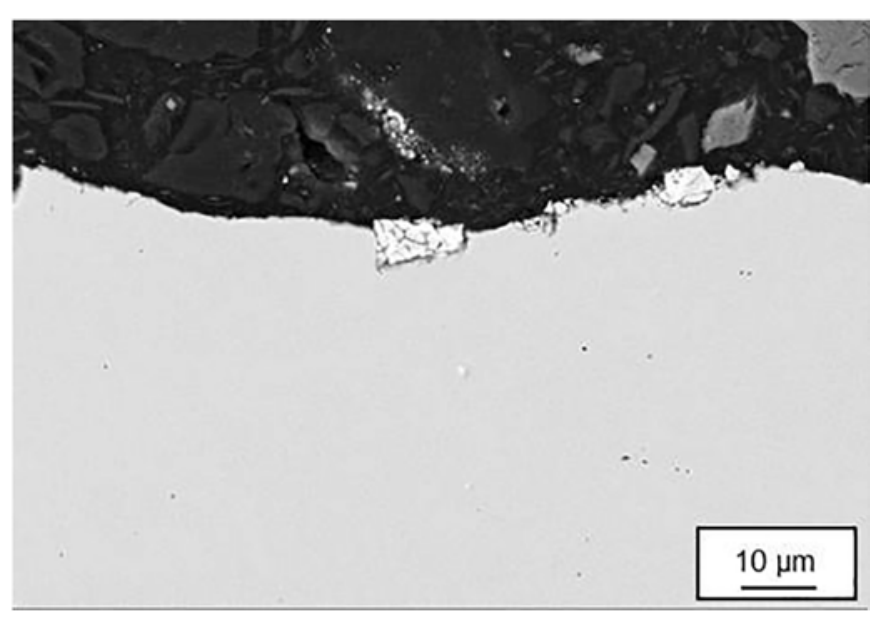

Fig. 3. Zirconium residuals in CSP sample.

\section{Results and discussion}

\subsection{PRELIMINARY study for electropolishing condition}

Initially, CSP and SSP samples were electropolished at different voltages of 2, 3, 5 and $7 \mathrm{~V}$ with the aim of finding a suitable combination between shot peening and EP treatment parameters. In Table 3, all considered combinations of parameters are listed.

Surface roughness and water contact angle, parameters of utmost importance from the point of view of biomedical application, were characterized for all the above series (Fig. 1). Regarding surface roughness, arithmetical mean height of the surface $\left(\mathrm{S}_{\mathrm{a}}\right)$ was selected as a representative parameter for roughness characterization. The roughness values obtained by confocal microscopy represented in Fig. 1, show the surface topographical evolution of shot peened surfaces after EP with different voltages. In both CSP and SSP surfaces, the trend is that roughness decreases at higher voltages (Fig. 1a). Nevertheless, behaviour of the peened surfaces for SSP samples when EP has been carried out at $3 \mathrm{~V}$ is opposite; while in CSP surfaces a sharp decrease in $S_{a}$ is observed for this voltage, in SSP surfaces the $S_{a}$ parameter increased. This behaviour could be attributed to the finer grain size generated by SSP treatment, as SSP process is known to induce notable grain refinement compared to CSP [3,4,27]. Differences between CSP and SSP are remarkable when maximum height $\left(\mathrm{S}_{z}\right)$ of each surface are compared (Fig. 1b). Although in both cases, $S_{z}$ parameter decrease after EP (excluding SSP-2 V), SSP samples maximum height is higher. Anodic behaviour of surfaces during EP at low voltages could involve active dissolution rather than polishing. The rate of active dissolution at a certain voltage depends on the surface defects and the grain size [28]. Since the atoms located in the proximity of grain boundary and further crystalline defects are energetically more favourable, they are preferentially removed during active dissolution. On randomly oriented crystals or in the presence of a high density of imperfections, as it is the case for SSP sample, the nucleation of monoatomic steps is fast. Monoatomic steps moving at different rates provoke the formation of microscopically observable etch patterns [25] and this could lead to an increase in surface roughness. This behaviour is not observed in CSP surfaces that are characterized with coarser grain size; the results suggest that, the voltage that led to active dissolution for SSP surfaces could have been enough to accomplish the EP process in case of CSP series.

Regarding the wettability measurements (Fig. 1b), SSP treated samples showed generally higher water contact angle compared to the CSP ones. After EP, water contact angle decreased at higher voltages, exhibiting similar values when $7 \mathrm{~V}$ condition was applied in both cases. $\mathrm{EP}$ in general resulted in higher surface wettability for shot peened samples. Therefore, the results indicate that apart from being affected by grain refinement and surface roughness [3], wettability is also promoted by the EP process.

Taking the trend of roughness and wettability variation into account, application of EP using 5 and $7 \mathrm{~V}$ to CSP and SSP series were selected to be further analysed, since these series represented a good combination of low surface roughness and higher wettability.

\subsection{MORPHOLOGICAL CHARACTERIZATION}

The decrease of surface roughness and water contact angle are consistent with FE-SEM and confocal microscopes observations used for morphological characterization. Fig. 2 represents the surface morphology after shot peening and EP treatments.

Before EP, SSP treated surface presents a higher density of impact induced dimples and surface defects compare to the CSP treated surface. After application of EP-5V, the surface of CSP samples show lower
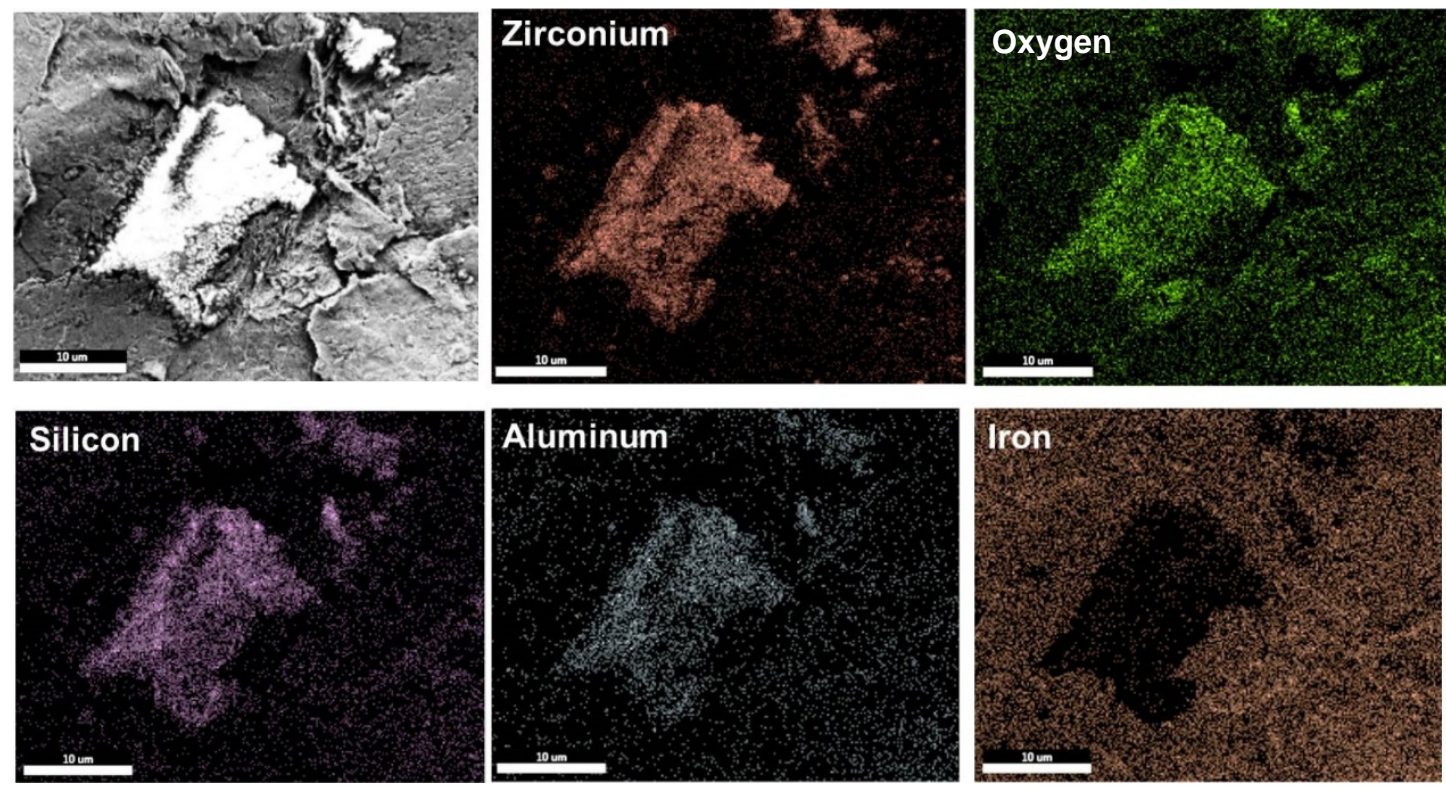

Fig. 4. EDS mapping of contaminated surface with residuals of zirconia shots. 


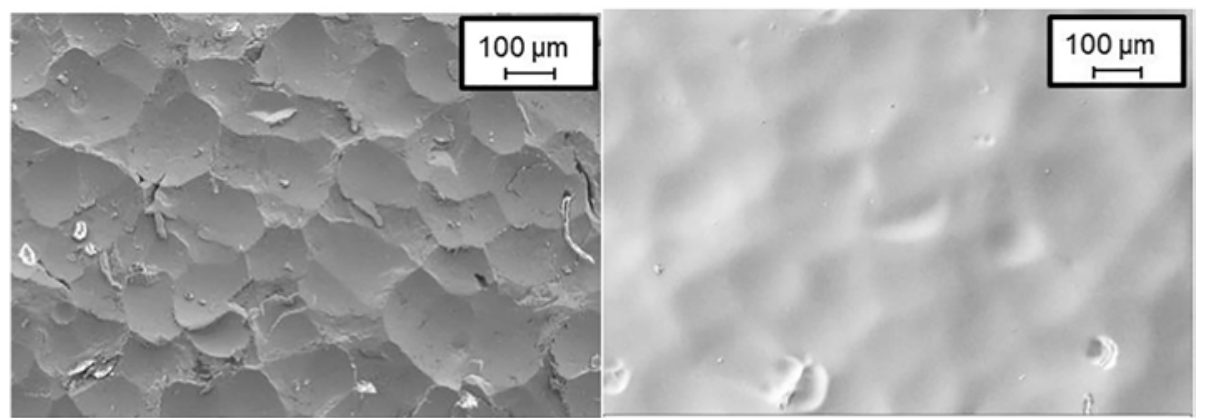

Fig. 5. CSP sample surface area before (left) and after electropolishing with $5 \mathrm{~V}$ (right).

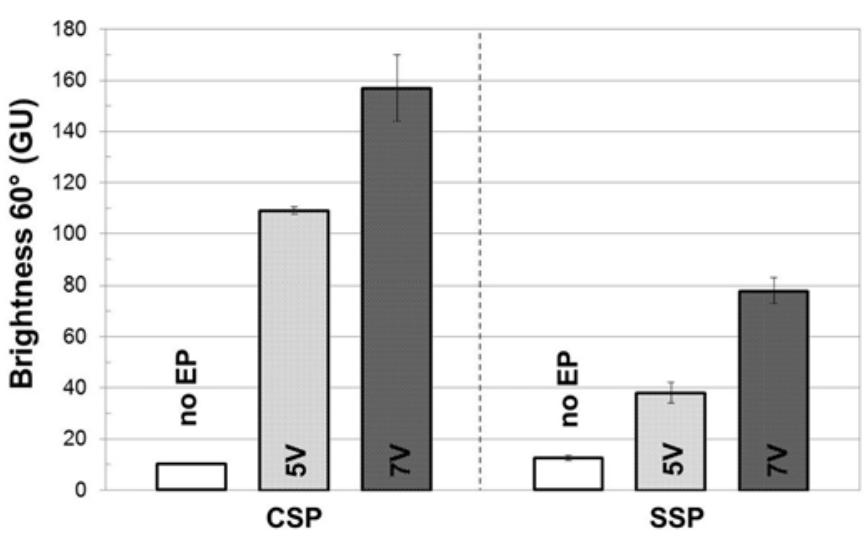

Fig. 6. Brightness measured at $60^{\circ}$ for CSP and SSP samples before and after EP with 5 and $7 \mathrm{~V}$.

roughness and a few remaining deep defects, in contrast with SSP samples that present higher quantity of dimples, as a result of higher kinetic energy of the process. Application of EP with the highest voltage $(7 \mathrm{~V})$, seems to be strong enough to remove defects produced by CSP, but not enough to completely eliminate those induced by SSP treatment; a small quantity of dimples are still visible on the surface.

\subsection{SURFACE CONTAMINATION}

As a consequence of shot impacts, some embedded fragments of the shots were detected at the top surface layer, as it can be observed on the cross-sectional view of a CSP sample shown in Fig. 3.

Chemical element identification was performed by EDS, as shown in Fig. 4. Apart from zirconium and oxygen, silicon and aluminium were

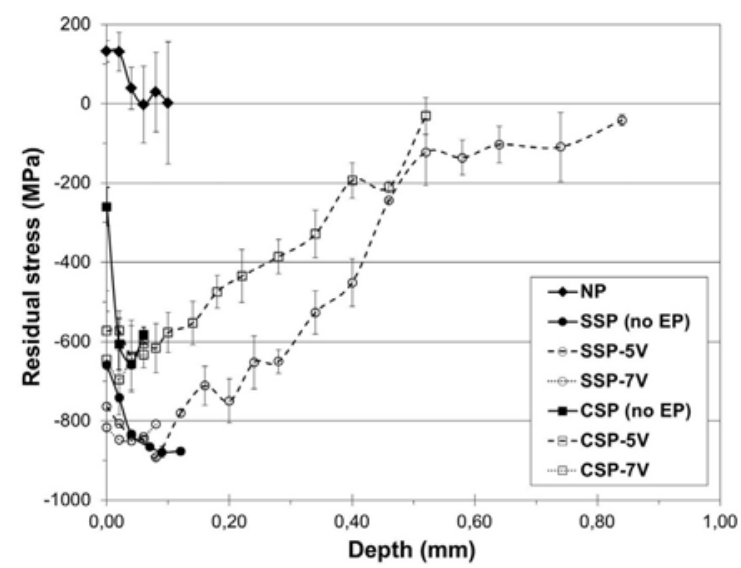

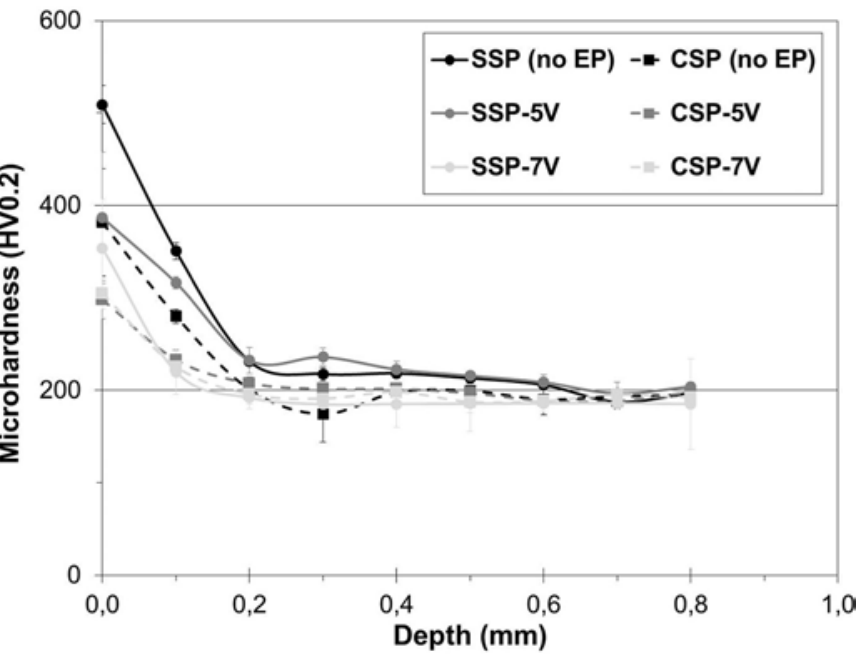

also detected, both of which are present at low percentages in the

Fig. 8. In-depth microhardness profiles.

composition of the Zirconia shots. Thus, the EDS analysis confirmed that during both CSP and SSP treatments, some zirconia shots were disintegrated and embedded at the treated surfaces.

The presence of these residues can have harmful effects on the behaviour of surfaces depending on the target application. Such residuals can produce instability from the point of view of mechanical properties (stress concentrator), and also play a role as initial sites for corrosion. Therefore application of EP seems crucial to decontaminate the surface and remove these shot remains (see Fig. 5).

\subsection{Brightness MEASUREMENTS}

The results of brightness evaluation of shot peened samples before

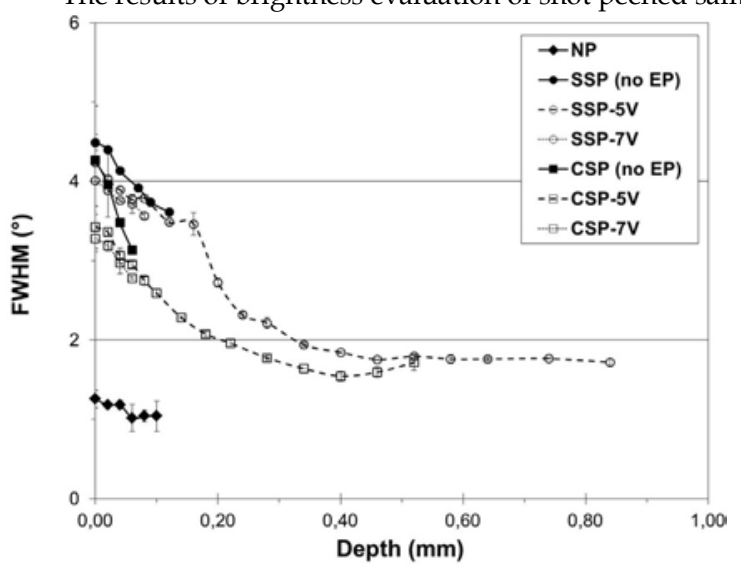

Fig. 7. a) Residual stress and, b) FHWM parameter in-depth distribution. 
and after EP, presented in Fig. 6, indicate that the brightness increased after EP, as expected, and higher brightness was observed for samples at electropolished at $7 \mathrm{~V}$ condition. The results point out a remarkable double fold brightness difference between CSP and SSP series.

\subsection{RESIDUAL stresS MEASUREMENTS}

Distributions of residual stresses and FWHM parameter, obtained by means of X-ray diffractometer for each condition, are respectively shown in Fig. 7 (a) and Fig. 7 (b) as a function distance from the treated surface.

During the EP process, a very thin layer of material is removed from the surface, therefore, the top surface of samples exhibit higher compressive stresses. The thickness of the layer affected by compressive residual stresses induced by shot peening is estimated to be around $0.5 \mathrm{~mm}$ and $0.9 \mathrm{~mm}$ respectively for CSP-5 V and SSP-5 V samples. The higher kinetic energy of the SSP treatment has caused the notable difference between these thicknesses.

The FWHM profile, as a cumulative index of hardening and grain refinement, also exhibits the effect of shot peening parameters; the FWHM parameter increased owing to the work hardening induced by shot peening treatments on the near surface layer compared to the NP series. FWHM trend is similar to that of the compressive residual stresses. As the distance from the surface increases, the FHWM parameter decreases until reaching values in the core of material similar to the NP series, similar behaviour comparing with other works [29].

\subsection{MICROHARDNESS MEASUREMENTS}

In depth microhardness profile of all samples is shown in Fig. 8. The results indicate that shot peening treatment increased the microhardness at the top layer of material due to the high energy impacts ( $500 \mathrm{HV}$ forSSP), which work harden thesurfacelayer.Similarhardness values have been reported with otherSP methods in 316L stainless steel [30]. As a result of EP, a quarter of reduction of surface microhardness is observed. Nevertheless, the microhardness values after shot peening and EP (305 HV for CSP-7 V and 355 HV for SSP-7 V) were still higher than the typical microhardness of stainless steel 316L ( 200 HV) [31]. The thickness of the layer where microhardness increased with respect to the core material was around $0.2 \mathrm{~mm}$.

\section{Conclusions}

The effects of electropolishing process after different shot peening treatments were evaluated through careful examination of physical and mechanical properties, using different combinations of treatment parameters. On the basis of the obtained results the following conclusions are drawn.

- Electropolishing was found efficient in considerably decreasing the surface roughness when $5 \mathrm{~V}$ and $7 \mathrm{~V}$ is applied after shot peening treatments.

- In conventionally shot peened series, after electropolishing the surface dimples were much less observable, compared to the severely shot peened series with slightly visible shot impact marks.

- It seems that electropolishing reduce the presence of embedded fragments of residual shots and smooth the surface of shot peened samples.

- Electropolishing, enhanced surface brightness inducing highly bright appearance for both shot peened series.

- Evaluation of water contact angle indicated that surface wettability was improved after electropolishing, regardless the electropolishing parameters.

\section{Funding sources}

The authors would like to thank to the Principado de Asturias government for the financing support given to the IDI/2018/000134 project.

\section{References}

[1] V. Schulze, Modern Mechanical Surface Treatment: States, Stability, Effects, (2006).

[2] S. Bagherifard, R. Ghelichi, M. Guagliano, On the shot peening surface coverage and its assessment by means of finite element simulation: a critical review and some original developments, Appl. Surf. Sci. 259 (2012) 186-194.

[3] S. Bagherifard, S. Slawik, I. Fernández-Pariente, C. Pauly, F. Mücklich, M. Guagliano, Nanoscale surface modification of AISI 316L stainless steel by severe shot peening, Mater. Des. 102 (2016) 68-77.

[4] J. González, L.-B. Peral, C. Colombo, I. Fernández Pariente, A study on the microstructural evolution of a low alloy steel by different shot peening treatments, Metals (Basel). 8 (3) (2018) 187.

[5] J. González, S. Bagherifard, M. Guagliano, I. Fernández Pariente, Influence of different shot peening treatments on surface state and fatigue behaviour of $\mathrm{Al} 6063$ alloy, Eng. Fract. Mech. 185 (2017) 72-81.

[6] S. Bagherifard, I. Fernandez-Pariente, R. Ghelichi, M. Guagliano, Effect of severe shot peening on microstructure and fatigue strength of cast iron, Int. J. Fatigue 65 (2014) 6470 .

[7] S. Bagherifard, et al., Effects of nanofeatures induced by severe shot peening (SSP) on mechanical, corrosion and cytocompatibility properties of magnesium alloy AZ31, Acta Biomater. 66 (2018) 93-108.

[8] O. Unal, R. Varol, Surface severe plastic deformation of AISI 304 via conventional shot peening, severe shot peening and repeening, Appl. Surf. Sci. 351 (2015) 289-295.

[9] O. Unal, R. Varol, Almen intensity effect on microstructure and mechanical properties of low carbon steel subjected to severe shot peening, Appl. Surf. Sci. 290 (2014) 40-47.

[10] M. Novelli, J.J. Fundenberger, P. Bocher, T. Grosdidier, On the effectiveness of surface severe plastic deformation by shot peening at cryogenic temperature, Appl. Surf. Sci. 389 (2016) 1169-1174.

[11] S. Bagherifard, R. Ghelichi, A. Khademhosseini, M. Guagliano, Cell response to nanocrystallized metallic substrates obtained through severe plastic deformation, ACS Appl. Mater. Interfaces 6 (11) (2014) 7963-7985.

[12] S. Bagherifard, R. Ghelichi, M. Guagliano, Numerical and experimental analysis of surface roughness generated by shot peening, Appl. Surf. Sci. 258 (18) (2012) 6831-6840.

[13] A. Zammit, M. Bonnici, M. Mhaede, R. Wan, L. Wagner, Shot peening of austempered ductile iron gears, Surf. Eng. 33 (9) (2017) 679-686.

[14] K.M. Kim, H.S. Shim, M.J. Seo, D.H. Hur, Corrosion control of alloy 690 by shot peening and electropolishing under simulated primary water condition of PWRs, Adv. Mater. Sci. Eng. 2015 (2015)

[15] J. Göske, et al., Surface characterization of corundum-blasted implants in hip arthroplasty, Microsc. Anal. 18 (5) (2004) 9-11.

[16] A.E. Medvedev, H.P. Ng, R. Lapovok, Y. Estrin, T.C. Lowe, V.N. Anumalasetty, Effect of bulk microstructure of commercially pure titanium on surface characteristics and fatigue properties after surface modification by sand blasting and acid-etching, J. Mech. Behav. Biomed. Mater. 57 (2016) 55-68.

[17] B.W. Darvell, N. Samman, W.K. Luk, R.K.F. Clark, H. Tideman, Contamination of titanium castings by aluminium oxide blasting, J. Dent. 23 (5) (1995) 319-322.

[18] M. Böhler, et al., Adverse tissue reactions to wear particles from Co-alloy articulations, increased by alumina-blasting particle contamination from cementless Ti-based total hip implants, J. Bone Jt. Surg 84 (1) (2002) 128-136.

[19] G.A. Vara, E.J. Butrón, M. BelénGarcía-Blanco, Challenges and opportunities in next generation of electropolishing surfaces, Surf. Eng. 31 (6) (2015) 397-398.

[20] Z. ur Rahman, K.M. Deen, L. Cano, W. Haider, The effects of parametric changes in electropolishing process on surface properties of 316L stainless steel, Appl. Surf. Sci. 410 (2017) 432-444.

[21] A.M. Awad, N.A.A. Ghany, T.M. Dahy, Removal of tarnishing and roughness of copper surface by electropolishing treatment, Appl. Surf. Sci. 256 (13) (2010) 4370-4375.

[22] P. Sojitra, et al., Surface enhancement and characterization of L-605 cobalt alloy cardiovascular stent by novel electrochemical treatment, Trends Biomater. Artif. Organs 23 (2) (2009) 55-64.

[23] E. Kassab A. Marquardt L. Neelakantan M. Frotscher F. Schreiber T. Gries S. Jockenhoevel J. Gomes G. Eggeler, "On the electropolishing of NiTi braided stents - challenges and solutions," Mater. Sci. Eng. Technol., vol. 45, no. 10, pp. 920-929, 2014.

[24] Y. Murakami, Metal Fatigue Effects of Small Defects and Nonmetallic Inclusions, (2002).

[25] G. D. and M. K. Sung-Ki LYU, Katsumi IOUE, "Effect of surface treatments on the strength of carburized gears," KSME Int. J., vol. 12, no. 2, pp. 206-214, 1998.

[26] "ISO 25178 - geometrical product specifications (GPS) - surface texture: areal.," Int. Organ. Stand.

[27] S. Bagheri, M. Guagliano, Review of shot peening processes to obtain nanocrystalline surfaces in metal alloys, Surf. Eng. 25 (1) (2009) 3-14.

[28] D. Landolt, Fundamental aspects of electropolishing, Electrochim. Acta 32 (1) (1987) $1-11$.

[29] S. Bagherifard, et al., The influence of nanostructured features on bacterial adhesion and bone cell functions on severely shot peened 316L stainless steel, Biomaterials 73 (2015) 185-197.

[30] V. Azar, B. Hashemi, M. Rezaee Yazdi, The effect of shot peening on fatigue and corrosion behavior of 316L stainless steel in Ringer's solution, Surf. Coatings Technol 204 (21-22) (2010) 3546-3551.

[31] S.A. Acerinox, ACX 240/Cr-Ni-Mo austenitic stainless steel corrosion resistance, pp. 1-2, (2015). 